time. The effects of the above cannot be ruled out.

Undoubtedly, with their excellent study design the authors have proved that cognitive impairment occurs in chronically ill bipolar affective disorder patients, but whether this reflects an integral part of the disease process remains to be determined.

McKay, A. P., Tarbuck, A. F., Shapleske, J., et al (1995) Neuropsychological function in manic-depressive psychosis. British Journal of Psychiatry, 167, 51-57.

S. BHANDARI

Fairfield Hospital

Bedfordshire SG5 4AA

\section{Visual fields in Gilles de la Tourette Syndrome}

SIR: Gilles de la Tourette (GTS) is a complex disorder characterised by multiple motor and one or more vocal tics (DSM-III-R; APA, 1987). It has been shown that GTS is a genetic disorder and the inheritance pattern is consistent with autosomal dominant transmission with incomplete but high penetrance (Eapen, 1993). In such a disorder there is always a quest for biological markers. Enoch et al (1988) described anomalous kinetic visual fields in $100 \%$ of children with GTS. It was suggested that visual field defects may serve as a genetic marker for GTS. Repka \& Singer (1992) performed automated static perimetry on 18 children with GTS. They demonstrated field defects in $25 \%$ of cases, however, they observed that these rates approximated to those observed in patients undergoing first time visual field testing.

We undertook a prospective controlled study to which 12 GTS patients ( 24 eyes), and 12 (24 eyes) age, sex-matched controls were recruited. No ocular disease was detected in any of the subjects, none had previously undergone visual field testing. Visual field tests were performed using a Humphrey Field Analyser running a central 24-2 full threshold test. Data collected included mean deviation (MD) scores, an indication of the overall field abnormality and corrected pattern standard deviation (CPSD) scores, localised field defects. Twenty-one out of 24 visual field tests in each group were reliable according to the reliability indices built into the field analyser software and were included in statistical analysis. There were no statistically significant differences in either MD $(P=0.08)$ or CPSD $(P=0.21)$ between GTS and control eyes (see Table 1 for results for Humphrey fields). The difference in MD approached significance, and a larger sample might be expected to yield a significant result. However, the MD score for a particular patient would not serve as a biological marker for GTS since there is a large overlap of MD scores in the GTS and control groups. Our study indicates a trend for a higher negative MD score in GTS patients, but we conclude that visual fields do not serve as a useful biological marker.

American Psychiatric Association (1987) Diagnostic and Statistical Manual of Mental Disorders (3rd edn, revised) (DSM-IIIR). Washington, DC: APA.

Table 1

Results of Humphrey 24-2 fields

\begin{tabular}{|c|c|c|c|c|c|c|c|c|c|}
\hline \multirow[b]{3}{*}{ Sex/Age } & \multicolumn{4}{|c|}{ GTS patients } & \multirow[b]{3}{*}{ Sex/Age } & \multicolumn{4}{|c|}{ Controls } \\
\hline & \multicolumn{2}{|c|}{ MD } & \multicolumn{2}{|c|}{ CPSD } & & \multicolumn{2}{|c|}{ MD } & \multicolumn{2}{|c|}{ CPSD } \\
\hline & $R$ eye & L eye & $R$ eye & $\bar{L}$ eye & & $R$ eye & L eye & $R$ eye & L eye \\
\hline $\begin{array}{l}\text { M } 22 y \\
F 46 y \\
F 51 y \\
M 23 y \\
M 50 y \\
F 52 y \\
M 20 y \\
F 29 y \\
M 21 y \\
M 29 y \\
M 50 y \\
F 31 y\end{array}$ & $\begin{array}{l}-2.70 \\
-3.22 \\
-2.27 \\
-9.72 \\
-0.70 \\
-2.78 \\
-3.40 \\
-1.69 \\
-2.10 \\
-2.58 \\
-2.10 \\
-3.25\end{array}$ & $\begin{array}{l}-2.02 \\
-2.33^{\circ} \\
-2.36 \\
-13.9^{\circ} \\
-1.66 \\
-1.67 \\
-1.92 \\
-2.55 \\
-0.96 \\
-2.08 \\
-0.96 \\
-3.21\end{array}$ & $\begin{array}{l}0.00 \\
2.50 \\
0.00 \\
7.27 \\
1.38 \\
1.07^{\circ} \\
0.00 \\
0.00 \\
1.26 \\
0.97 \\
1.26 \\
0.20\end{array}$ & $\begin{array}{l}0.00 \\
0.00^{*} \\
4.06 \\
9.60^{*} \\
0.00 \\
0.00 \\
1.43 \\
1.79 \\
1.79 \\
0.00 \\
1.79 \\
0.00\end{array}$ & $\begin{array}{l}\text { M } 23 y \\
F 44 y \\
F 50 y \\
M 24 y \\
\text { M } 46 y \\
F 51 y \\
\text { M } 23 y \\
F 22 y \\
\text { M } 21 y \\
M 32 y \\
\text { M } 48 y \\
F 32 y\end{array}$ & $\begin{array}{r}-1.68 \\
0.08 \\
-2.84 \\
-1.46 \\
-0.24 \\
-0.77 \\
-1.29 \\
-0.78 \\
-2.33 \\
-1.26 \\
-1.78 \\
-8.39\end{array}$ & $\begin{array}{r}-1.64 \\
0.16 \\
-4.63 \\
-1.38 \\
0.63 \\
-1.25 \\
-1.17 \\
-1.17 \\
-0.53 \\
-0.40^{\circ} \\
-2.53 \\
-7.86^{\circ}\end{array}$ & $\begin{array}{l}0.00 \\
1.12 \\
0.00 \\
0.00 \\
0.52 \\
0.00 \\
0.39 \\
0.60 \\
0.00 \\
1.11 \\
1.32 \\
3.75\end{array}$ & $\begin{array}{l}0.92 \\
0.00 \\
5.48 \\
0.00 \\
0.00 \\
0.00 \\
0.00 \\
1.23 \\
1.45 \\
1.34^{\circ} \\
0.00 \\
4.56^{\circ}\end{array}$ \\
\hline
\end{tabular}

•low reliability score (excluded from statistical analysis). 
Eapen, V., Pauls, D. L. \& Robertson, M. M. (1993) Evidence for autosomal dominant transmission in Gilles de la Tourette Syndrome - United Kingdom cohort. British Journal of Psychiatry, 162, 593-596.

ENOCH, J. M., ItZhaKi, A., LAKShminarayanan, V., et al (1988/ 89) Anomalous kinetic visual fields in Gilles de la Tourette Syndrome patients and family members. Perimetry Update, 77-84.

RePKA, M. X. \& Singer, H. S. (1992) Gilles de la Tourette syndrome and the afferent visual system. Neuro-ophthalmology. $12,367-374$

\section{A HUNDRED YEARS AGO}

\section{The alleged increase of insanity}

It is eminently satisfactory that the Lunacy Commissioners are beginning to recognise the importance of age incidence in the consideration of the statistics of insanity with a view to the determination of the problem whether the constant increase in the number of the insane under treatment in England and Wales really signifies an increasing prevalence of lunacy, or rather of occurring cases of insanity. In their recent annual reports it is true that the Commissioners have constantly expressed their opinion that the large increase in the number of known lunatics is mainly due to causes other than an increase in the prevalence of insanity as an active disease. They have, however, until now turned a deaf ear to the urgent appeal for statistics of the ages of the patients annually admitted to the lunatic asylums, and of the ages of the patients who die year by year in those asylums. We are glad to note in the recently issued report a first instalment of such age statistics, which, if continued for a series of years, and if amplified, will in a few years afford the means of throwing much light upon this important and interesting problem. It is pointed out that in recent years there has been a marked increase in the number and proportion of admitted cases of mental decay resulting solely from old age. In proof of this the Commissioners show that in 1883 the admissions to asylums of persons aged upwards of sixty years were equal to $12.5 \%$ of the total admissions; in 1888 this proportion had increased to $13.2 \%$; and in 1893 it had further increased to $14.7 \%$. These statistics are based upon information contained in the annual reports issued by county and borough asylums, and conclusively prove that the cases admitted above the age of sixty years have increased at a far more rapid rate than the admissions under that age. These cases represent, probably, to a large extent transfers from workhouses to asylums, but from whatever cause the increase arises it can scarcely be seriously asserted that this increase of cases of senile mental decay represents an increase of true insanity. These figures, moreover, throw some light upon the age incidence of the persons returned in England and Wales as mentally deranged at the three Censuses in 1871, 1881, and 1891. The ratio per 1000 of the English population returned as mentally deranged under the age of forty-five years was 2.24 in $1871,2.29$ in 1881 , and 2.26 in 1891 . Thus the ratio of insanity to population at these ages remained practically stationary during this period of twenty years. Above the age of forty-five years, however, the calculation of the ratio of insanity gives very different results; the ratio was 6.35 per 1000 in $1871,7.40$ in 1881 , and 8.02 in 1891 . In the absence of information as to the ages of cases admitted to asylums it was impossible to ascertain how much of this increased incidence of mental derangement upon elderly persons was due to what may correctly be called the accumulation of cases caused by improved treatment of the insane in asylums, and how much to an increase in the number of admissions of cases of senile dementia. The figures given in the Lunacy Commissioners' last report established beyond doubt the steady increase, both actual and relative, in the admission of cases of so-called insanity above the age of sixty years. The important bearing of these figures in the direction of disproving the reality of the alleged increase of insanity in this country will, it may be hoped, induce the Commissioners to give more complete statistics of the ages of the annual admissions to all asylums for the insane in future reports.

\section{Reference}

Lancet, 17 August 1895, 416-417.

Researched by Henry Rollin, Emeritus Consultant Psychiatrist, Horton Hospital, Epsom, Surrey. 